\title{
MANAGEMENT OF ACUTE ANTERIOR INFERIOR DISLOCATION OF SHOULDER BY MILCH METHOD AT MIMS, MANDYA: A RETROSPECTIVE STUDY
}

\author{
Pandarinath Ashvathnarayanarao1, Manjappa Chitanahalli Narasimhe Gowda², Amaradeep Govindappa ${ }^{3}$
}

${ }^{1}$ Assistant Professor, Department of Orthopaedics, Mandya Institute of Medical Sciences, Mandya.

2 Professor and HOD, Department of Orthopaedics, Mandya Institute of Medical Sciences, Mandya.

${ }_{3}^{3}$ Assistant Professor, Department of Orthopaedics, Mandya Institute of Medical Sciences, Mandya.

\begin{tabular}{l}
\hline ABSTRACT \\
\hline BACKGROUND \\
Acute anterior inferior dislocation of shoulder is a common orthopaedic emergency affecting up to $60 \%$ of all major joint \\
dislocation..$^{1-5}$, most common is anterior inferior type. ${ }^{6-7}$; variety of techniques has been described, Milch method in zero position is \\
an effective method of closed reduction without admission/medication.
\end{tabular}

\section{METHODS}

This retrospective study was carried out at MIMS, Mandya, from Dec. 2014 to Feb. 2016. A total number of 30 patients aged from 22 to 60 were included in the study as per inclusion criteria with symptoms and signs of anterior dislocation and dislocation reduced by Milch.

\section{RESULTS}

Age range in our study was between 22 and 60 years; 26 were male (80\%), 4 were female (20\%), right sided 20 (60\%), left sided $10(30 \%)$. Post reduction few were given analgesic for a few days and were asked to remove immobiliser after 3 weeks and all were asked to undergo shoulder rehabilitation exercises.

\section{CONCLUSION}

Milch Techniques appears to be sound procedure and treating orthopaedician should be aware of other techniques when situation warrants.

\section{KEYWORDS}

Dislocation Shoulder/Milch Method without Admission/Medication.

HOW TO CITE THIS ARTICLE: Ashvathnarayanarao P, Gowda MCN, Govindappa A. Management of acute anterior inferior dislocation of shoulder by Milch method at MIMS, Mandya: a retrospective study. J. Evolution Med. Dent. Sci. 2016;5(40):2436-2438 DOI: $10.14260 /$ jemds/2016/567

\section{INTRODUCTION}

Shoulder dislocations account for almost $50 \%$ of all joint dislocations presenting to emergency departments.[1] Very often, shoulder dislocations are anterior (90-98\%) and occur as a result of trauma.[2,3] Other types being posterior, inferior, (Subluxatio Erecta) fracture dislocation.6,7 Ideal reduction methods should be quick, effective and as painless as possible for patients; and they should not cause iatrogenic complication. Traditional techniques to reduce the dislocated glenohumeral joint can be painful to the patient and may also be associated with further injury.[4-6] The Milch method is a relatively new technique which is reported to be safe, comfortable and reliable.[7] This study was conducted to report our experiences of using the Milch method (ERM) to reduce traumatic anterior shoulder dislocations and to evaluate the causes of failure. The following discussion confined to anterior shoulder dislocation. Most dislocations can be reduced in the emergency department by different methods. ${ }^{8,9,10}$ Most methods require admission/medication, not with Milch method.

Financial or Other, Competing Interest: None.

Submission 12-04-2016, Peer Review 03-05-2016,

Acceptance 06-05-2016, Published 18-05-2016.

Corresponding Author:

Dr. Pandarinath Ashwathnarayanarao,

Old Doctors Quarters No-3,

MIMS Compound

Mandya-571401.

E-mail: pandari_hema@yahoo.co.in

DOI: $10.14260 /$ jemds/2016/567

\section{DIFFERENT METHODS}

A. Traction/Counter Traction. 10,11,12 $^{1}$ In adduction-Hippocrates method. ${ }^{13}$

Forward flexion-Stimson's.

B. Leverage

Kocher. ${ }^{14}$

Milch. ${ }^{15}$

C. Scapular Manipulation

D. Miscellaneous-Direct Pressure/Pulsion

In the present study we use Milch method, which is simple, not requiring medication/admission.

\section{MATERIAL AND METHODS}

This study was carried out at Department of Orthopaedics, MIMS, Mandya, from Dec. 2014 to Feb. 2016. A total number of 30 patients aged from 22 to 60 were included in the study as per inclusion criteria with symptoms and signs of anterior dislocation without any fracture. There were 26 male and 4 female patients that were subjected to X-ray investigation. After obtaining informed consent they were included in the study; dislocation reduced by Milch. ${ }^{16}$ method (Method initially outlined by Ashley Cooper in 1825, later introduced by Milch in 1938; zero position with forward flexion and overhead abduction resulted in all perihumeral muscles at shoulder lies in a line parallel to shaft humerus).

\section{Inclusion Criteria}

Anterior dislocation confirmed clinically and radiologically. 


\section{Exclusion Criteria}

1. Posterior and inferior dislocation.

2. Associated fracture of humerus and scapula.

3. Neural injury.

4. Vascular injury.

5. Recurrent dislocation.

6. History of manipulation.

\section{The Procedure followed in Milch Method as follows Steps}

1. Patient in supine position. Treating surgeon on the side of dislocation, right sided, places right hand on the right shoulder, fingers support top of the shoulder, thumb under surface of dislocated humeral head to hold it in position.

2. Elbow of the affected arm put in $90^{\circ}$ flexion, treating surgeon's left hand gently abducts the arm to overhead position.

3. As the arm is abducted, externally rotates. ${ }^{17}$

4. Humeral head in axilla reduces into glenoid fossa/gently pushed by thumb. ${ }^{18}$

If unable to achieve reduction by single attempt, second attempt was tried without giving any sedation. If failed after second attempt, patient was administered with IV sedation. Then third attempt was tried under sedation. Following reduction, shoulder immobilized by shoulder immobilizer for three weeks after check x-ray. Analgesics was administered to patient on the basis of their pain severity. All 30 patients were asked to remove immobilizer after 3 weeks and everyone undergone shoulder examination for instability. All were asked to undergo shoulder rehabilitation exercises.

\section{RESULTS}

Total number of patients 30 in our study and all were treated on outpatient basis in casualty emergency department. Age range in our study was between $22-60$ years, 26 were male (80\%), 4 were female (20\%), right sided 20 (60\%), left sided $10(30 \%)$. Mode of injury of 15 patients were RTA, 10 patients were self-fall and 5 patients were assault. Time duration from injury occurrence to presentation to the hospital was 20 patients presented within 3 hours, 8 patients within 6 hours and 2 patients within 24 hours; 20 patients undergone reduction by single attempt of Milch method; 8 patients undergone reduction by second attempt of Milch method; 2 patients undergone reduction by third attempt of Milch method after giving IV sedation. Post reduction around 5 patients were given analgesic for a few days. All 30 patients were asked to remove immobilizer after 3 weeks and all were asked to undergo shoulder rehabilitation exercises. There were no post reduction complication or any other complication; eventually no complications were reported in our study.

\section{DISCUSSION}

Shoulder dislocation is the commonest joint to be dislocated and can be reduced by different methods of reduction. Among them both External Rotation and Milch method of reduction can be done easily with good rate of success without any anaesthesia. The reduction methods commonly used for shoulder dislocation depend upon either traction or leverage. Traction increases muscle spasm and require more force that cause more difficult and painful and less likely to get success.

In Milch method, leverage principle is used. There is belief that traction is necessary to overcome the muscle spasm when reducing shoulder dislocation; however, Milch Technique not using traction has good success rate in selected cases. Technique is physiologically sound, mechanism relay upon careful manipulation of humeral head around obstructions, blocking its path back to glenoid fossa. When this technique is correctly used, arm in zero position requires no force, reducing the risk of secondary injuries to the joint and surrounding structures. It is arguable that the technique relaying solely on traction to overcome muscle spasm should not be used; an understanding the anatomy of shoulder in dislocation is essential in attempting reduction. The position of humerus such that the resultant force of perihumeral muscle lies parallel to shaft of humerus, which help to minimize the muscle force and reduction is achieved easily. Mirick et al and Leidelmeyer. ${ }^{19}$ recommended use of intravenous anaesthesia for patients with a dislocation for the first time; however, in our study 28 (92\%) of the 30 successful reductions were performed without the use of sedation in patients who had a dislocation for the first time.

The present study shows that a Milch method is easier to perform and have high chance of success. Even without any sedation and anaesthesia patients experience less pain, so that after procedure patients can be sent home immediately which decreases the hospital cost. This is similar to the study done by different authors. There was no short term complication in our series. This method can be done safely for acute dislocation immediately as patients arrive to the hospital and after reduction patients can be discharged immediately which decreases the hospital stay, health resource utilization. Furthermore, there is no requirement of anaesthesia in majority of cases which itself decreases the anaesthetic hazards. As we have not used the pain scale in our study, we were unable to quantify the pain which is the weakness of the study. Further research needs to be dedicated to studying the mechanics of reduction techniques. ${ }^{20}$ and their effects on the pathoanatomy of the dislocated shoulder.

\section{CONCLUSION}

Milch techniques appears to be a sound procedure and treating orthopaedician should be aware of other techniques when situation warrants.

\section{REFERENCES}

1. Ceroni D, Sadri H, Leuenbrger A. Anteroinferior shoulder dislocation: an auto-reduction method without analgesia. J Orthop Trauma 1997;11(6):399-404.

2. Kothari RU, Dronen SC. Prospective evaluation of the scapular manipulation technique in reducing anterior shoulder dislocation. Ann Emerg Med 1992;21(11):134952.

3. McNamara RM. Reduction of anterior shoulder dislocations by scapular manipulation. Ann Emerge Med 1993;22(7):1140-4.

4. Te Shaa RL, Wijffels MPO, Marti RK. Questionnaire reveals variations in management of acute first time shoulder dislocations in Netherlands. Eur J Emerg Med 2003;10(1):58-61.

5. Villarin LA, Belk KE, Freid R. Emergency department evaluation and treatment of elbow and forearm injuries. Emerg Med Clin North Am 1999;17(4):843-58, vi. 
6. Plummer D, Clinton J. The external rotation method for reduction of acute anterior shoulder dislocation. Emerg Med Clin North Am 1989;7(1):165-75.

7. Gleeson AP. Anterior glenohumeral dislocations: what to do and how to do it. J Accid of Emerg Med 1998:15(1):712.

8. Daya M Shoulder. ln: Rosen P, ed. Emergency medicine: concepts and clinical practice. St, Louis: Mosby: 1998;4th edn:728-9.

9. Uehara DT, Rudzinski JP. Injuries to the shoulder complex and humeras. ln: Tintinalli JE, Kelen DG, Stapczynski JS, eds. Emergency Medicine: a comprehensive study guide. New York: Mcgraw Hill 2000; $5^{\text {th }}$ edn:1783-91.

10. Rebel GD, McCabe JB. Anterior shoulder dislocation: a review of reduction techniques. Am J Emerg Med 1991;9(2):180-8.

11. Mattick A, Wyatt JP. From hippocrates to eskimoa history of techniques used to reduce anterior dislocation of the shoulder. JR Coll Surg Edinb 2000;45(5):312-6.

12. Nicola T. Acute anterior dislocation of the shoulder. J Bone Joint Surg Am 1949:31(1):153-9.

13. Adama F. The internet classics archive; instruments of reduction by hippocrates, (Cited 2003 Oct 18). Available fronrhttp://cissies.mit,edu/Hippocrates/reduct 5.5. html
14. Canales Cortes V, Garcia-Dihinx Chec L, Rodriguez Vela J. Reduction of acute anterior dislocations of the shoulder without anaesthesia in the position of maximum muscular relaxation. Int Orthop 1989;13(4):259-62.

15. Milch $H$. Treatment of dislocation of the shoulder. Surg 1938;3(5):732-40.

16. Saha AK. The classic. Mechanism of shoulder movements and a plea for the recognition of zero position of glenohumeral joint. Clin Orthop 1983;173:3-10.

17. Garmavos C. Technical note: modifications and improvements of the Milch technique for the reduction of anterior dislocation of the shoulder without premedication. J Trauma 1992;32(6):801-3.

18. Mirick MJ, Clinton JE, Ruiz E. External rotation method of shoulder dislocation reduction. JACEP 1979;8(12):52831.

19. Leidelmeyer R. Reduced! s shoulder, subtly and painlessly. Emerg Med 1977;9:233-4.

20. Krishna KE, Rajesh M, Surya B, et al. The external rotation method for reduction of acute anterior dislocations and fracture-dislocations of the shoulder. Journal of Bone \& Joint Surgery 2004;86(11):2431-4. 